\title{
Últimos emprendimientos edilicios Ciudad Universitaria / Santa Fe, Argentina
}

Mg. Arq. Osvaldo Mansur

Docente investigador FADU/UNL

\section{Predio}

El predio de la Ciudad Universitaria tiene un emplazamiento inmejorable dentro la ciudad de Santa Fe, no sólo por su proximidad respecto del área central sino también por estar dotado de características únicas en términos de accesibilidad, extensión, calidad ambiental y por poseer las cualidades estéticas y paisajísticas generadas por el entorno natural y artificial circundante. La extensión y localización del implantamiento se asimila con claridad a sus orígenes históricos en los gimnasios de la antigüedad griega. Platón de Atenas instala su Academia en los jardines de Acádemos, de donde deriva su nombre. Los griegos establecían una estrecha relación entre el atletismo, la educación y la salud.

La presencia urbana de su estructura edilicia, su reconocimiento social, se efectiviza a través de la Ruta Nacional $N^{\circ} 168$, un eje vial interurbano e internacional de cuantioso caudal que hace efectiva la vinculación de la incipiente área metropolitana constituida por las ciudades de Santa Fe, Paraná y sus respectivas áreas de influencia.

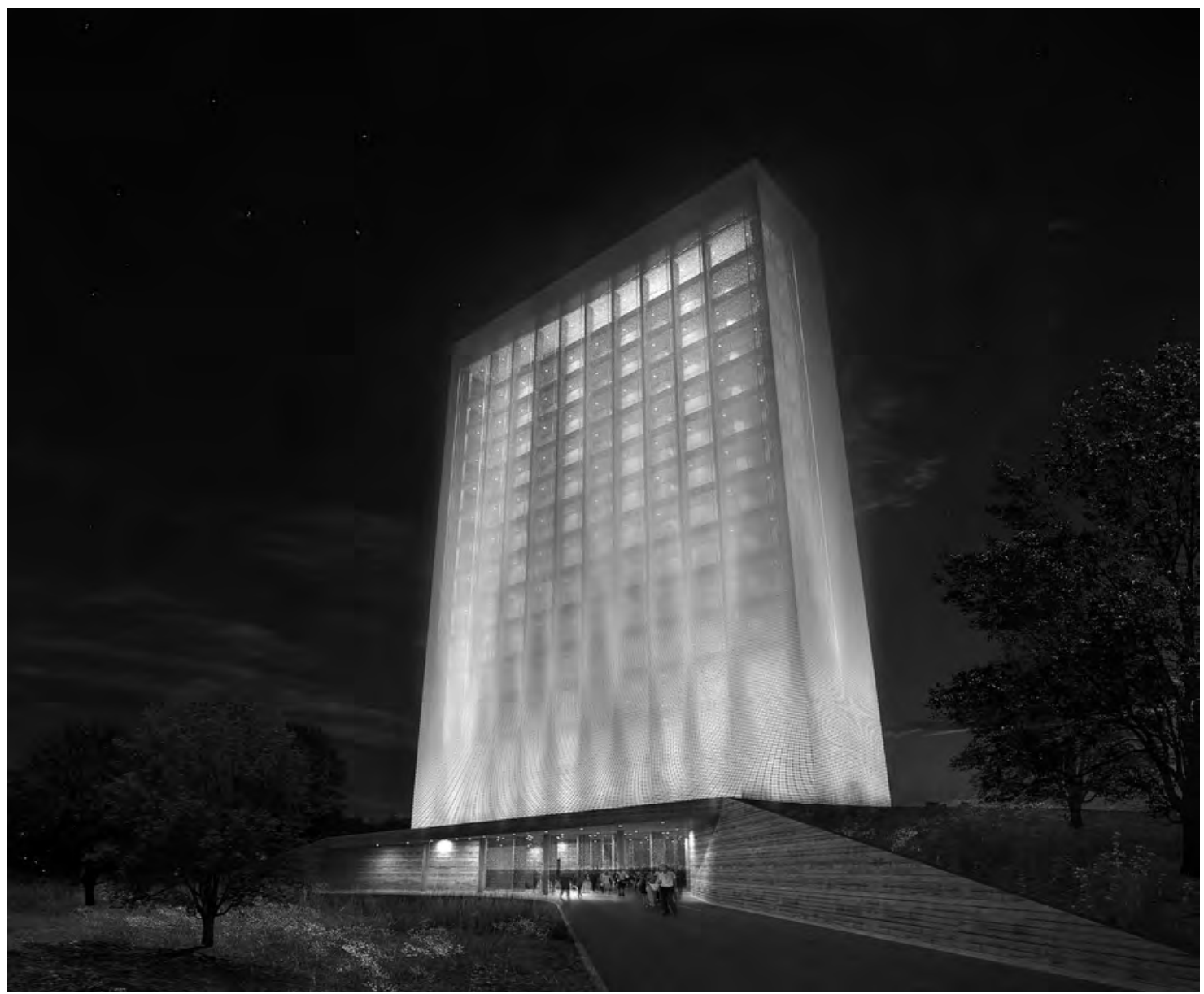




\section{Estructura inicial}

El conjunto edilicio que originó su ocupación inicial, actualmente integrado por las Facultades de Ciencias Hídricas, Bioquímica, Arquitectura y Humanidades, tiene un desarrollo lineal paralelo a la Ruta Nacional $N^{\circ} 168$, y se constituye en una masa edilicia ordenada por ese eje y conformada por un conjunto articulado de volúmenes que expresan con una severa sinceridad su materialización constructiva. Esta expresión estética es el resultado de un posicionamiento frente a la disciplina basado en lo que Edward de Zurko llamó la «analogía moral», por la que la obra de arquitectura debía expresar sin tapujos ni atenuantes la verdadera naturaleza intrínsica de su constitución, la auténtica legitimación y reafirmación ontológica de sus componentes constructivos y funcionales.

El autor del proyecto original, arquitecto Efren Lastra, se refería a estos fundamentos invocando el término «desnudez arquitectónica». Esta aludida y convocada desnudez, bajo la determinación selectiva de un elemento constructivo dominante y excluyente para todo el conjunto -el ladrillo-, conduce a una expresión estética sólidamente integrada, inequívocamente unificada e invariablemente uniformada.

Bajo la fuerte impronta determinada por esta construcción original, las intervenciones que le sucedieron debieron tenerla en cuenta con operaciones proyectuales y estrategias propositivas de diversa y variada índole, como veremos luego.

Más allá de la expresión arquitectónica, el proyecto evidencia influencias de la arquitectura sistémica de la época, más preocupada por lo conceptual y la indeterminación que por el objeto único perfecto y acabado, un enfoque abierto que ha permitido incorporar adecuadamente las intervenciones que se le realizaron a posteriori.

\section{ISM}

El Instituto Superior de Música es un edificio que opta por la asimilación casi plena a esta estructura. Lo realiza sin formular grandes gestos o comentarios arquitectónicos a partir de los cuales se pueda inferir una fecha cierta de su ejecución, distanciada de la estructura primitiva a la que se asocia. Tampoco hace mención o expresa el carácter diferencial de su función (música). De esta manera, contribuye no sólo a reafirmar sino también a ampliar la construcción dominante enfatizando su importancia y magnitud. La espacialidad interior de esta unidad académica es un hecho destacable, aunque podría haber sido reforzada mediante el uso de la circulación vertical (escalera) en uno de sus límites que innecesariamente enmudece o ciega una de sus caras.

\section{Cubo}

La ampliación de la Facultad de Arquitectura, en cambio, elige otra estrategia. A diferencia del Instituto Superior de Música desarrolla un programa edilicio que es ampliatorio de una unidad académica preexistente, razón que, en principio, invalida las posibilidades y potencialidades expresivas que podrían haber derivado de una nueva función edilicia. No obstante, la preocupación dominante de este nuevo proyecto se centra en otra variable: el tiempo. Se ha tratado de manifestar con la mayor claridad y elocuencia posible que la nueva obra pertenece al tiempo presente. Con esta operación se corría el riesgo de diseñar un edificio totalmente desprendido no sólo de la estructura madre sino también de la unidad académica a la cual pertenece.

Pero esto no ha ocurrido. Delicadas operaciones de diseño han permitido establecer la fecha cierta buscada, es decir, la expresión actualizada del estado del arte,

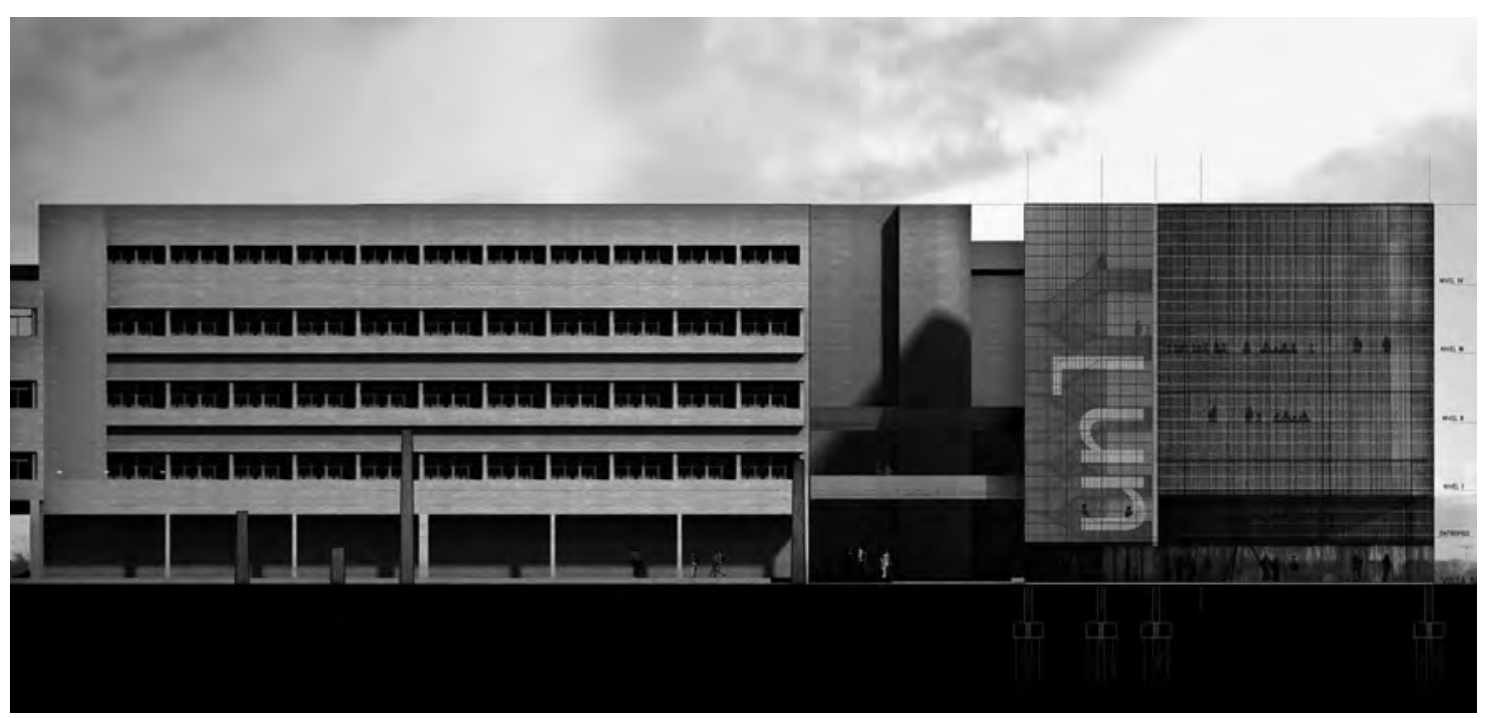




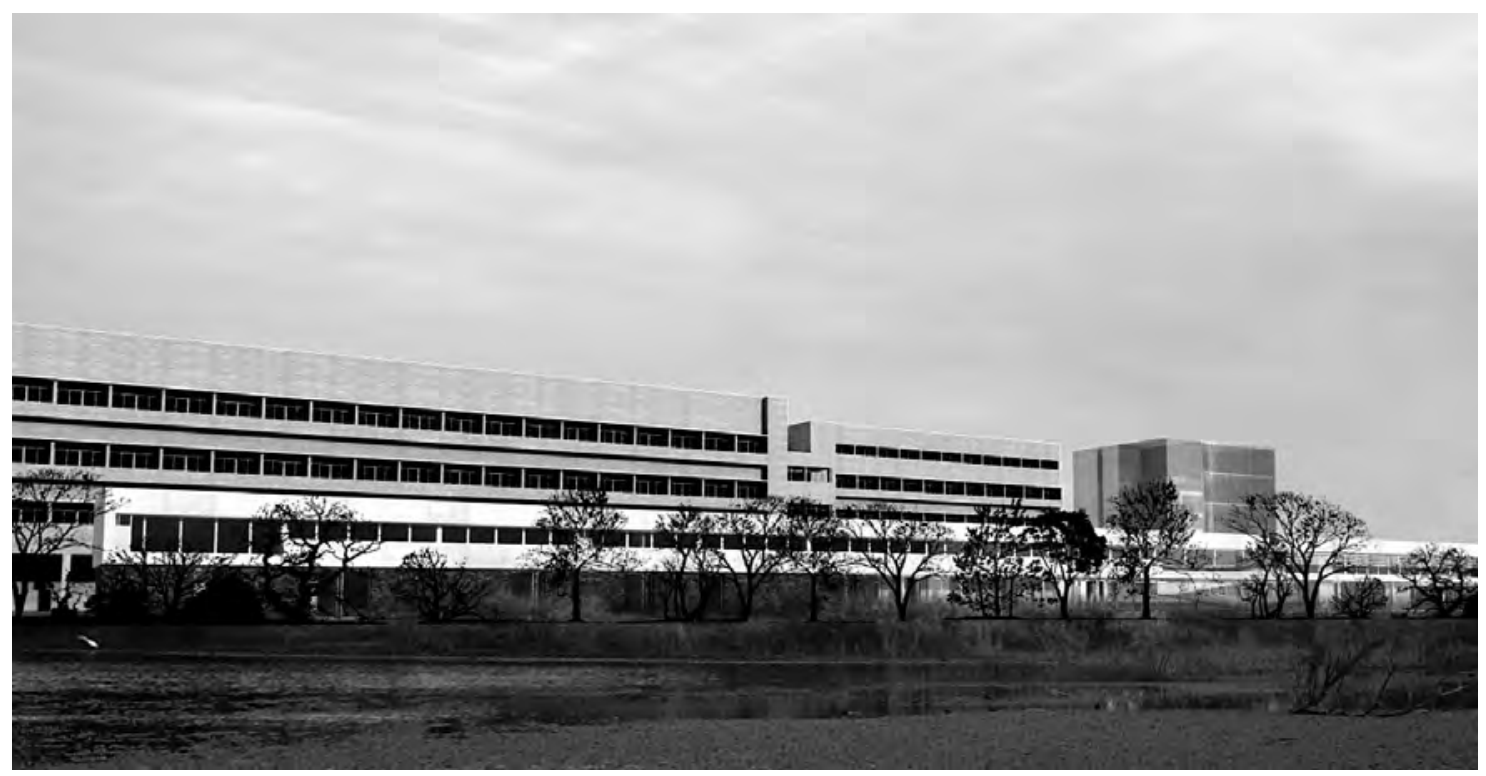

aunque simultáneamente manifestando la pertenencia a la estructura original. Se ha encontrado un equilibrio adecuado entre las tensiones antagónicas que operan en este tipo de intervención. Por una parte, la inserción edilicia dentro del contexto y, por la otra, la identificación de la obra con los tiempos presentes.

La primera variable (inserción) se pudo garantizar inicialmente mediante la unificación irrestricta de la altura edilicia, operación volumétrica que produce asimilación y reciprocidad de las masas construidas. Luego, mediante la utilización de un lenguaje materializado con elementos únicos, operación planimétrica que desarrolla el concepto de unidad de la envolvente y se asimila perfectamente con la austeridad y la uniformidad de la masa muraria de las instalaciones preexistentes, característica excluyente aludida en párrafos anteriores. La segunda variable (identificación) se expresa con nitidez, en primer término por adoptar la posición exenta o aislada, que le permite manifestar su autonomía geométrica como cubo independiente, y luego a partir del desarrollo de un lenguaje arquitectónico contemporáneo, liviano y transparente que, además, muestra una preocupación recurrente por el problema paradigmático de nuestro siglo, el de la sustentabilidad ambiental. Lo manifiesta a través de la utilización de una piel envolvente independiente y exenta, destinada a amortiguar, tamizar o morigerar los efectos del clima sin afectar o reducir los niveles de luminosidad natural que requieren los ambientes interiores. Esta operación de responsabilidad ambiental es adecuada e ilustrativamente llevada al extremo en el muro oeste a través de la utilización de una pantalla de protección casi ciega, con pequeñas perforaciones, evitando los efectos negativos que esta orientación geográfica produce en nuestro clima.

\section{Reserva}

El aulario del edificio Reserva es una estructura límite que debe, por un lado, resolver su encuentro y proximidad con la Reserva Ecológica del predio universitario y, por el otro, su vinculación con la estructura edilicia principal. Asume frente a la Reserva una actitud de fuerte contrastación expresando con una severidad inusitada su constitución tridimensional materializada en una caja prismática geométricamente pura. Este contraste tan marcado refuerza y enfatiza el carácter antinómico de ambas entidades: naturaleza y artificio, razón que permite incrementar la valoración autónoma de sus propias potencialidades así contrapuestas: el orden libre frente al orden impuesto.

Por el contrario, frente a la edificación existente asume una actitud de franca y generosa humildad, reduciendo ostensiblemente su estatura para permitir las transparencias visuales desde esas instalaciones existentes hacia la belleza natural de la Reserva. Esta actitud contrapuesta también se expresa en el techado de su estructura, el que, en lugar de contrastar, se asimila a la naturaleza para prolongar y extender los efectos visuales de la Reserva enfocada en altura desde la antigua estructura edilicia. Esta vocación de respeto y asimilación de esta estructura con las construcciones existentes también se manifiesta con claridad en las imágenes que muestran al aulario visto desde la Reserva Ecológica, en las que el nuevo edificio se presenta como una extensión emergente con naturalidad de la propia estructura madre, repitiendo las tensiones dominantes del volumen y las reglas compositivas del lenguaje arquitectónico, materializado en bandas horizontales. Con destreza y astucia, se presenta como una ampliación del edificio original, como si hubiera sido prevista desde los primeros tiempos pero sin perder su identidad con el presente. 
El adecuado distanciamiento y la regulación de las alturas edilicias entre el Aulario y la estructura madre posibilitaron la creación de un ámbito abierto de generosas dimensiones y adecuado calibre espacial, lo que, sumado a su posicionamiento estratégico respecto de las vías circulatorias, le asegura una utilización provechosa para actividades lúdicas y de expansión.

Por tratarse de un construcción separada de la planta madre, la conexión funcional entre ambas estructuras reviste una importancia vital. Se materializa a través del eje de penetración oeste, que, por su jerarquía y sus cualidades espaciales, puede llamarse con seguridad eje institucional. En la escala urbana, a estos ejes se los llama monumentales dado su rol trascendente en la organización de la estructura urbana y las cualidades simbólicas que emergen de ese rol. Todas las tensiones edilicias y paisajísticas confluyen en el punto de encuentro de este eje institucional con el edificio del Aulario, estableciéndose en este cruce un ámbito jerarquizado de carácter tridimensional y alturas múltiples a partir del cual se establece la vinculación física y el reconocimiento espacial de los componentes programáticos principales del edificio y en donde también se produce el contacto visual inmediato e impactante de la Reserva Ecológica.

\section{Eje institucional}

El eje institucional antes indicado recibió un impulso importante, una definición categórica a partir de la ejecución de la plaza del Bicentenario. El eje atraviesa el predio en toda su extensión y lo hace con continuidades visuales absolutas desde su inicio en el límite del terreno con la ruta nacional hasta su finalización en la Reserva Ecológica. En el encuentro con este eje, tanto la estructura principal como el futuro Aulario adquieren la tipología histórica conocida como Arco del triunfo, que es la que posibilita su atravesamiento pasando por una instancia adecuada que posibilita y potencia las continuidades físicas, al tiempo que enmarca, pone en foco y valoriza las sucesivas aproximaciones a las instalaciones edilicias y a los ámbitos de expansión. Las operaciones aquí realizadas nos remiten al método clásico de la composición desarrollada por Jean Nicolas Durand en París antes de que naciera la arquitectura moderna.

\section{Hotel}

El edificio del Hotel expresa con una sinceridad inusitada que se trata de una entidad no académica. Lo hace a través de la adopción de una tipología edilicia que no reconoce antecedente alguno dentro del predio universitario: el edificio en torre. Es la única construcción con desarrollo vertical dominante; todas las demás, por el contrario, tienen desarrollo horizontal dominante.

Adoptando técnicas y materiales de reconocida actualidad-cristales reflexivos o grillas metálicas-, logra producir efectos de comunicación impactantes y policrómicos a partir del manejo diestro de la reflexión lumínica durante el día o de la iluminación artificial durante la noche y su debido control matizado por los tamices protectivos de la piel envolvente. Algunos autores asimilan esta multiplicidad de efectos cambiantes y efímeros, logrados por las cualidades evanescentes de la piel envolvente, a la representación materializada del mundo inmaterial de los ordenadores, es decir, las lógicas de la virtualidad constituidas en símbolo a través del lenguaje de la arquitectura. De esta manera, la totalidad edilicia del Hotel adquiere una importante dimensión significativa en términos de comunicación; en realidad se trata de un objeto hipercomunicativo traducido en clave gestáltica, cualidad que resulta no sólo ponderable sino también útil y provechosa por tratarse de una actividad que debe promoverse al público durante las 24 horas, todos los días. Es probable que, con el tiempo, se transforme en un jalón indicativo que permita una fácil e inmediata localización del predio universitario. La pureza geométrica del prisma vertical pudo mantenerse mediante la aplicación de ingeniosas ondulaciones artificiales que permiten elevar el plano natural del suelo para poder disponer, por debajo de este plano, las instalaciones especiales que hubieran alterado la configuración prismática de la torre. Consecuentemente, en términos visuales, desde el interior del predio el prisma se apoya sobre el plano natural del terreno; en cambio, desde el eje de reconocimiento y comunicación (Ruta $N^{\circ} 168$ ), el prisma se apoya (visualmente) sobre un puente construido al efecto, cuyos extremos se pierden en el terreno natural, sugiriendo algún parentesco o referencia tangencial con la obra maestra de nuestra arquitectura designada como Casa del puente de Amancio Williams. Inusuales pero efectivas y simples operaciones tecnológicas permitieron también excluir los emergentes superiores del prisma, tales como tanques de agua o salas de máquinas, siempre con la lograda intención de mantener la pureza de la geometría adoptada.

\section{Residencias}

Finalmente las unidades de residencia estudiantil introducen una variedad programática relevante en el predio porque incorporan, juntamente con el Hotel, la presencia de personas en horarios nocturnos. Esto contribuye a vitalizar el área mediante la generación de usos diversificados emergentes de esta actividad y principalmente, porque permite mejorar las condiciones de seguridad en el predio debido al componente disuasivo que provoca la presencia de personas en el sitio en tiempos y horarios de inactividad académica.

La condición programática diferencial como entidad no académica pudo haber sido destacada a partir de la elección de tipos edilicios diferenciados de lo académico. Una organización con tensiones edilicias distribuidas en las dos dimensiones del plano podría haber marcado una diferencia sustancial con las tipologías existentes, 

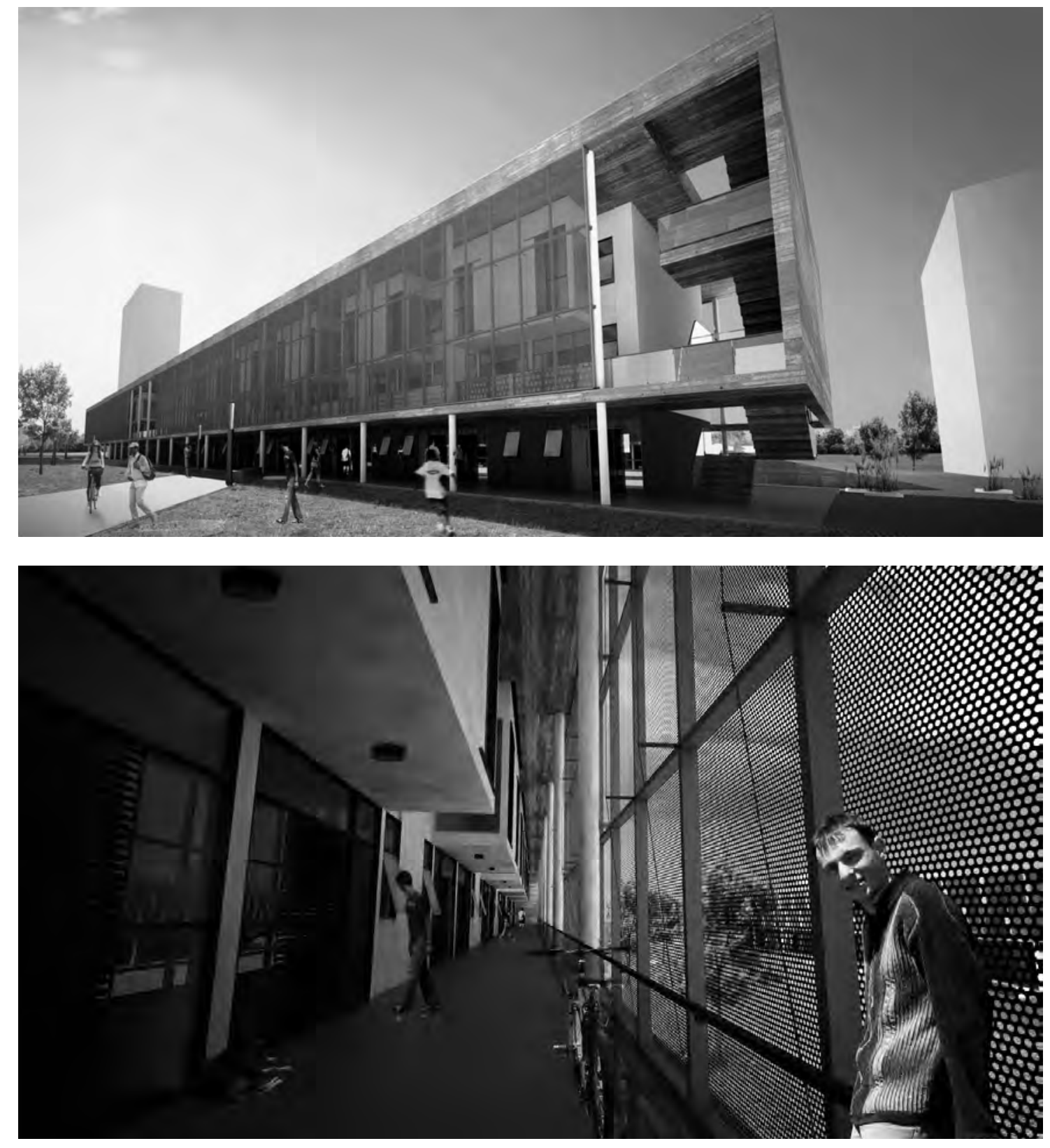
haciendo hincapié en el rol no académico de la institución residencial. Sin embargo, al igual que en los nuevos aularios, se adoptó por la conformación de tiras desarrolladas en el sentido este-oeste.

Como elemento distintivo y ponderable del proyecto, se destaca un eje circulatorio central que conecta ambas tiras con las instalaciones complementarias y con el resto del campus. Este eje impacta sorprendentemente en su encuentro con lo edilicio a través de un ámbito muy calificado espacialmente, con la escala de acontecimiento multitudinario, cualidades que le permitirán constituirse en un lugar de encuentros y socializaciones sugestivo y convocante. Trasunta una imagen de unidad del conjunto en torno a un elemento jerarquizado que lo referencia.

\section{Consideraciones finales}

Los diferentes enfoques expuestos se presentan como nociones que se revisan continuamente, se complejizan o reelaboran de acuerdo con la particularidad o contingencia de cada proyecto más que como etapas superadoras de las anteriores.

Es necesario señalar algunas condiciones que son comunes a la totalidad de los diseños antes señalados a partir de algunos elementos subyacentes que se repiten en todos ellos y que permiten percibir la unidad del conjunto. Principalmente, se deben destacar las que tienen que ver con la trascendencia e importancia que se le ha asignado a la toma inicial de partido para cada intervención particular, es decir, a la elección de las tensiones dominantes y de la tipología edilicia para cada implantación y programa, a partir de lo cual se produce la subordinación coherente y consistente del conjunto de las operaciones posteriores que la refuerzan y acompañan. A este posicionamiento se lo suele indicar como arquitectura de partido o Escuela de Buenos Aires, la que incorpora a figuras muy destacadas de nuestro país. También debe mencionarse la rigurosidad geométrica de los componentes estructurales, la racionalidad y sistematicidad de las operaciones tecnológicas y constructivas, y una preocupación casi obsesiva por el detalle, asegurando la calidad y correspondencia del producto ejecutado.

En una perspectiva más global o generalizadora, que considere los aportes proyectuales realizados en los últimos tiempos en el campus universitario, resulta evidente un esfuerzo de coherencia muy marcado entre disciplina y profesión y una preocupación por obtener productos de máxima calidad en términos de diseño, tendientes a formular aportes significativos para la disciplina, realizados desde un enfoque contemporáneo que se vincula, por analogía, con aspiraciones centrales muy valiosas referidas a la enseñanza que se brinda desde la institución universitaria, esto es: actualización y excelencia.

Desde esta perspectiva, podemos concluir que las obras proyectadas representan con dignidad y orgullo a la institución a la que pertenecen y son modelos ejemplares 0 referentes insoslayables para las unidades académicas consagradas al diseño. 